\title{
On totally bounded universal algebras
}

\author{
Mitrofan M. Choban and InA D. Ciobanu
}

\begin{abstract}
.
In the class of topological algebras of a given signature the notions of totally boundedness and $a$-pseudocompactness are introduced. A topological algebra is totally bounded if it is a subalgebra of a compact algebra. The general properties of totally bounded algebras are studied. The compactifications of topological algebras are investigated too. In particular, the problem of the continuous extension of the operation on the Stone-Čech compactification is studied.
\end{abstract}

\author{
Department of Algebra, GeOMEtry and TOPOlOgy \\ TIRASPOL STATE UNIVERSITY \\ GH. IAblocichin 5, MD2069 ChişinăU, Republic OF Moldova \\ E-mail address: mmchoban@gmail.com
}

DEPARTMENT OF MATHEMATICS

BALti "Alecu Russo" State University

PUSHKIN 38, MD3100 BĂLŢI, REPUBLIC OF MOLDOVA

E-mail address: viorelina@yahoo.com 